\title{
Synthesis of Building Blocks for the Construction of Trialomethylated Heterocycles
}

\author{
Carlos E. Bencke, Mário A. Marangoni, Andressa S. Fortes, Cássio de A. Fantinel, \\ Hélio G. Bonacorso, Marcos A. P. Martins and Nilo Zanatta*
}

Núcleo de Química de Heterociclos (NUQUIMHE), Departamento de Química, Universidade Federal de Santa Maria, 97105-900, Santa Maria, RS, Brazil, Tel.: (55)32208756 Fax: (55)32208031

*e-mail corresponding author: zanatta@base.ufsm.br

Keywords: Trialomethylated Heterocycles, Reactions of Horner-Wadsworth-Emmons, Olefination

\section{INTRODUCTION}

Many trifluoromethylated heterocycles showing remarkable biological activity have been widely used in a variety of fields ranging from medicine to agricultural products, besides of being versatile intermediate for the synthesis of biologically active compounds containing trifluoromethyl groups. Among these trifluorinated compounds, stand pyridines, which have some approaches to preparation. The general procedures for synthesis of trifluoromethyl-pyridines are generally antimony catalysts, or $\mathrm{MoF}_{6}$ at high temperature and pressure. An alternative method involves direct introduction of trifluoromethyl groups in pyridine, using $\mathrm{CF}_{3} \mathrm{I}$ or $\mathrm{CF}_{3} \mathrm{Cl}$. However, these methods have some disadvantages such as high temperature and pressure, use of HF, low reactivity, low selectivity, limited scope and formation of sub products.

Thus, the development of synthetic methods for preparation of trifluoromethylpyridines and other heterocycles, it is highly desired. In this context, the use of simple trifluoromethyl building blocks has often proved to be a better choice than the direct trialomethylation methods.

Therefore, this work aims to developing an efficient methodology for the synthesis of convenient trialomethylated building blocks that will be used for the preparation of trialomethylated heterocycles.

\section{RESULTS AND DISCUSSION}

Scheme 1 reports the reaction method used for the synthesis of compounds $\mathbf{6 - 1 1} \mathbf{a - b}$. The synthesis of compounds described in Scheme 1 was based on reactions of Horner-Wadsworth-Emmons of $\beta$ alkoxivinyl-trialomethyl-ketones 1-5a-b and phosphinate 6 in THF with the addition of $\mathrm{NaH}$, leading to the formation of compounds 7-11a-b in good yields (Table 1 ). The reactions were carried out under reflux, stirring, and inert atmosphere. After $2 \mathrm{~h}$, the reaction mixture was purified by silica column chromatography using methanol/chloroform as eluents.
Figure 1. Synthesis of compounds 7-11a-b.

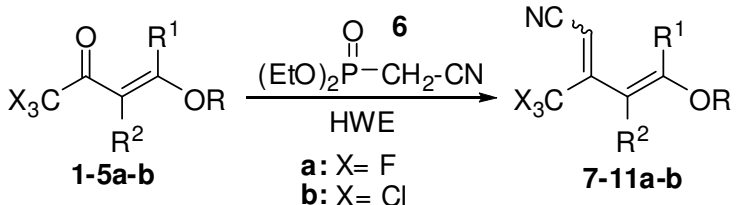

$$
\begin{aligned}
& \begin{array}{c|ccccc}
\# & \mathbf{1} & \mathbf{2} & \mathbf{3} & \mathbf{4} & \mathbf{5} \\
\hline \mathbf{R}^{1} & \mathrm{Me} & \mathrm{H} & \mathrm{H} & \mathrm{H} & \mathrm{H}
\end{array} \\
& \begin{array}{l|lllll}
\mathbf{R}^{2} & \mathrm{H} & \mathrm{Br} & \mathrm{H} & -\left(\mathrm{CH}_{2}\right)_{2^{-}} & -\left(\mathrm{CH}_{2}\right)_{3}- \\
\mathbf{R} & \mathrm{Me} & \mathrm{Et} & \mathrm{Et} &
\end{array}
\end{aligned}
$$

Table 1. Reaction condition used for the synthesis of

\begin{tabular}{|c|c|c|c|}
\hline$\#$ & Enone & Reaction condition $^{\mathrm{a}}$ & Yield $(\%)^{b}$ \\
\hline $7 a$ & 1 & $i$ & 36 \\
\hline $7 b$ & & $i$ & 30 \\
\hline $8 a$ & 2 & $i$ & 76 \\
\hline $8 b$ & & $i$ & 60 \\
\hline $9 a$ & 3 & $i$ & 71 \\
\hline $9 b$ & & $i$ & 81 \\
\hline $10 a$ & 4 & I & 49 \\
\hline $10 b$ & & $i$ & 60 \\
\hline $11 \mathrm{a}$ & 5 & $i$ & 80 \\
\hline $11 b$ & & $i$ & 55 \\
\hline
\end{tabular}
compounds 7-11a-b and yields.

${ }^{a}$ Reactions condition: $\mathrm{NC}-\mathrm{CH}_{2} \mathrm{P}(\mathrm{O})\left(\mathrm{OC}_{2} \mathrm{H}_{5}\right)_{2}, \mathrm{NaH}, \mathrm{THF}, 66^{\circ} \mathrm{C}$, $2 \mathrm{~h} .{ }^{\mathrm{b}}$ Yield of isolated products.

\section{CONCLUSION}

In this work, we reported a series of novel and important trifluoromethyl builging blocks 7-11a-b that will be used for the preparation of many trialomethylated heterocycles with promising biological potential.

\section{ACKNOWLEDGEMENTS}

The authors acknowledge the financial support of CNPq, CAPES and FAPERGS.

\section{REFERENCES}

${ }^{1}$ (a) Filler, R. Biochemical Aspects of Fluorine Chemistry; Kodansha: Tokyo, 1982. (b) Welch, J. T.; Eswarakrishnan, S. Fluorine in Bioorganic Chemistry; John Wiley \& Sons: New York, 1991.

${ }^{2}$ (a) Cox, J. M.; Gillen, et al Chem. Abstr. 1997, 126, 104006. (b) Toki, T. T.; et al Chem. Abstr. 1988, 109, 210902. (c) Fenstermacher, M. R.; Novoroske, R. L. Chem. Abstr. 1980, 92, 94255.

${ }^{3}$ (a) Nishiyama, R.; et al Chem. Abstr. 1982, 96, 181153. (b) Fung, A. P.; et al Chem. Abstr. 1984, 101, 171106. (c) Shustov, L. D.; et al Zh. Obshch. Khim. 1983, 53, 103.

${ }^{4}$ (a) Naumann, D.; Wikes, B.; Kischkewitz, J. J. Fluorine Chem. 1985, 30,73. (b) Juergen Kobayashi, Y.; et al Chem. Pharm. Bull. 1978, 26, 1247.

(c) Maki, Y. Chem. Abstr 1980, 92, 6416.

Volle, J-N.; Schlosser, M. Eur. J. Org. Chem., 2002, 9, 1490-1492. 